\title{
Student-Centered Learning and Current Practice in Bangladeshi College Education
}

\author{
Muhammad Jakir Al Faruki \\ Associate Professor, Rajshahi Government College, Bangladesh \\ Md. Armanul Haque (corresponding author) \\ Associate Professor, Information Science and Library Management, University of Rajshahi, Bangladesh. \\ Md. Mahbubul Islam \\ Associate Professor, Information Science and Library Management, University of Rajshahi, Bangladesh.
}

\begin{abstract}
Education reinforces the development of modern society. The construction of the developed nation mostly depends on the educational system of a country. The harmonious policy of administrators primarily influences the factors that enhance teaching and learning, welcoming attitude of teachers towards the students, adequate budget from the government end, the adaptation of technology into the educational system and adequate infrastructural facilities. Bangladeshi college education has a wider lack of those issues. This study explored the state of student centeredness of learning, technology involvement, its challenges and prospects. It highlighted the contemporary practice in Bangladeshi college education with a focus on the student centred learning and traditional learning. Besides, the research presented a critical reflection on the current practice. In this regard, an action plan for attaining the goal is offered. This study is entirely based on document study and the researchers' practical personal experience in practice.
\end{abstract}

Keywords student-centred learning, College education, Bangladesh.

DOI: $10.7176 / \mathrm{JEP} / 10-13-11$

Publication date:May $31^{\text {st }} 2019$

\section{Introduction}

To ensure proactive technology involved student-centred learning for internalising expected behavioural change in the learners is the central focus in modern day education. It is a paradigm shift from focusing teacher to learners in the system of education (O'Neil and McMahon,2005). The term student-centred learning entails that the learning only can valid when it goes through the active group participation with full learner responsibility based on stimulating critical thinking and reflective understanding (Felder and Brent, 1996).

Now Bangladesh is in dire need of such method and techniques to produce world-class graduates who lead the country in reaching the vision to be a developed nation by 2041(MOE, 2010). Bangladesh is a small country with its 170 million populations including endless potential in education. There is a significant learning population of 200 million who are going to enter the job market in a short period. So, these learning people face the challenge of entering the job market with their quality of education as learning and teaching that is still traditional. The learners do not feel much interested in classroom learning rather than interested in the coaching centre outside and want to manage certificates anyway (MOE, 2010; Hossain and Khan, 2014). Though Bangladesh Constitution puts due emphasis on universal, compulsory and mass-oriented education for generating motivated and skilled citizens (Ministry of Law, Article-17, 2016) the goal of the constitution is still far away to reach. That assertion implicated that meta-cognitive and useful idea of education appropriately emphasised in the composition. The academic community observed that it is because of the absence of student-centred learning in educational institutions involving modern technology, especially in the secondary and higher secondary level which is considered the foundation of higher education. For this reason, secondary and higher secondary education thought to be base of producing resourceful graduates which the country badly needs in this critical juncture of transition.

Considering this severe situation, in-depth inquiry on the learning method and social condition of the learning environment is needed. The researchers in this country and abroad suggest that shifting this widely less effective method of teaching and making quality education functioning; it is vital to change the attitude, motivation (Kim, Land \& Furlong, 2013), facilities, methods and practice. Taking this reality, discussed above, into consideration, the researcher wants to examine the issue in the perspective of Bangladeshi higher education in college level. Additionally, the research will enquire into the problem of implementing student-centred learning in a higher secondary school in Bangladesh and its prospects. This research also will investigate using and involving technology in higher education, more specifically undergraduate sociology class in Bangladesh. 
Modern technology made learning student-friendly and useful, as well as purpose-based and skill, oriented. Introducing and using technology in Bangladeshi educational institutions is a stiff challenge for educators. The government of Bangladesh and education planners acknowledged the situation in the current education policy (MOE, 2010). The government of Bangladesh sets 30 objectives in its present education policy and through them to put due emphasis for technology involvement, teachers training, motivate learners, learning with inquisitiveness and creativity, learning with ecstasy and enthusiasm. As a member of the professional learning community the researcher wants to explore the state of student centeredness of learning, technology involvement, its challenges and prospects through this study.

This study aims to:

(i) examine the present practice in Bangladeshi college education;

(ii) Present a brief review of the student centred learning and traditional learning;

(iii) give a critical reflection on the current practice;

(iv) Provide an action plan for attaining the goal.

This study is entirely based on document study and the researchers' practical personal experience in practice.

\subsection{Context and Current Practice}

\subsection{Background of College education in Bangladesh}

In our country, including my college, learning and teaching are not transformative, reflective and autonomous thinking oriented but it is mostly 'jug-and-mug'type- thought that teachers pour knowledge to the passive students to memorising, just memorising information for forgetting in future. In most cases, the student finds their study content irrelevant and become bored and apathetic to the learning. The reason behind the situation is policy, curriculum, teaching-learning methods in practice, education administration, inadequate infrastructure, inappropriate or insufficient technology accessibility, human quality and motivation-both in the educators and learners side.

Experts find learning, in the $21^{\text {st }}$ century, is a social process in the sociological term. Through the process, learners experience psychological (changing in understanding), convictional (revision of belief system and values) and behavioural (change in lifestyle) changes (Mezirow, 1997). All nations expect these kinds of changes in civic life through education. It is our understanding thatin the current technology dominated the globalised world, learning is both instrumental and communicative. Ineffective learning-acquiring skill and techniques for material life, the fact of an affirmation may be established through empirical examination (Mezirow, 1997; Habermas, 1981). However, communicative learning involves understanding purposes, values, beliefs, and feelings and person's reflexivity (Turner, 1995). In communicative learning, it becomes essential for learners to become critically reflective of the assumptions underlying intentions, values, beliefs, and feelings (Mizirow, 1997).

In Bangladesh, transforming the core value of society through education is almost a failed story. Even though there are attempts to novel teaching methods, effective learning is not active at all in the country (Hossain and Khan, 2014). Bangladesh is country of large numbers of educated but unemployed people, while around 35 thousand highly paid foreign employees remit \$2.35 billion per annum from Bangladesh to other countries (Alamgir and Haque, 2018) while millions of educated people remain either unemployed or underemployed. It manifested that Bangladesh failed to produce the necessary skilled workforce because of failure in education. Although Bangladesh has excellent achievement education, especially achieving literacy rate, gender mainstreaming in 
primary and secondary level and overall MDG achievement by 5015 but it faces a stern challenge to implement SDG-4 by 2030 for budgetary constraint and policy focus. Bangladesh spends only 1.9 per cent of total GDP which even the lowest in South Asia while nearest neighbours India and Pakistan pay 3.9 per cent, Pakistan-2.5 per cent respectively (Rahman et al., 2016).

Bangladesh faces several complex hurdles in achieving active learning at all level of education including a college education. Some sources of problems mentioned below:

- $\quad$ Scare resources.

- Low budget allocation in education. Bangladesh allocated 12.6 and 14.6 per cent of the budget in total education including ICT and technology respectively for the fiscal year of 2016-2017and 2017-2018 (Rahman et al., 2016).

- Budget allocation in Bangladesh education is below the international benchmark, the distribution in the education sector should be 20 per cent of the total budget, and expenditure in education should be 6 per cent of GDP, but Bangladesh is below then both standards (Habib, 2017).

- The teacher-student ratio is very high. (In 2016, 1:39 in primary, but no data available for higher education) Possibly the rate is higher in tertiary education.

- In $201580 \%$ of schools had electricity, while $38 \%$ had internet access. No data were available for college education. (Rahman et al., 2016).

- It has been observed that only a few teachers are trained and the standard of training is not above the reproach. Those who are trained did not practice in the classroom to cement their learning

- $\quad$ Education budget spent in the most in non-development purpose, for example, the salary of teachers and staff but not in the aspect of quality enhancement. A national daily makes a title in the way, 'Problem in Education: Quality not priority' (Habib, 2017; Alamgir,2018).

- It is observed that achieving quality education through curriculum, instruction and assessment Bangladesh introduces creative questions based on Bloom Taxonomy and constructivism (MOE,2012) for secondary and higher secondary level education though it is still not implemented in higher education. Around $60 \%$ of secondary and higher education level teacher received the original question doing training, but most of them were not well equipped in this kind of expertise. To our observation, most of them not understand the objectives, core idea and techniques of formative assessment (MOE,2015) and new summative evaluation as a whole.

- $\quad$ Three critical points related to implement the student-centred learning (SCL) in the country are: (1) pertaining to teaching-learning facilities- inadequate infrastructures, technology, electricity, ICT, quality expenditure, learning space, financial challenges for students and teachers, insufficient rewards and remuneration; (2) related to teaching community- training, expertise, sincerities, motivational, cultural; (3) pertaining to administrative arrangements- political, policy issues, good governance, teachers recruitment and existing political culture of the nation.

- In addition to reality as mentioned earlier, shortened or abuse of learning time by teachers and students is a complicated difficulty for the whole learning situation (Tietjen, 2004) in Bangladesh including a college education. Stumpy, irregular, and delayed attendance by teacher and students found almost every level of knowledge in the country including my college. Low level of teacher attendance, high rates of 
absenteeism, lack of punctuality, ineffective class-time use, and time- allocation to non-teaching duties are a steep setback in education.

It is observed that implementing SCL in college education in colleges, cultural and administrative problem is critically higher than those of scare resources and insufficient learning facilities, while resources and facilitiesare not insignificant anyway.

\subsection{Traditional VS Student-Centered learning}

Traditional lecture method is developed based on the idea of discipline, nondemocratic social system, where a teacher is the master and controller of learning situation and only source of information. Teachers pour knowledge into the empty container without caring for how much retaining there and regenerating further. Educators plan and design classrooms as well as create a rule for disciplining education environment wherein lecturing is the only tools for disseminating knowledge to learners. To organise the teaching-learning situation, they impose a seating chart and assign readiness to students. They create, tests, assign homework to the students and thereby asses learning outcome and assign a grade. The student has no scope to choose what they are to learn, how it be taught and why they are to learn.

More significantly, Students' capability, potentiality and reflectivity are, for the most part, ignored followed by just 'shut up and let me teach' approach of the teacher. That is why it is said that there is a lot of teaching, but no learning and this process is a waste of valuable time, human resources and resources. As a result, this process is just killing unlimited potentials and creativity of learners. As their students do not find any relevance with their won inquisitiveness, emotional attachment, persuasion of own needs and intuitive findings and thereby, learning becomes passive and apathetic information swallowing and eructating in the exam paper. Therein, students are pursuing only certificates anyway through private tuitions, coaching centre, guide and notebooks instead of self internalise values and new ideas. In this method, evaluation turns to assessment of learning not assessment for learning (MOE,2015).

On the contrary, student centred learning (SCL )or interactive learning places different idea of knowledge which puts student's needs, problem, interests, inquisitiveness in the centre where teacher facilitate, guide and helping to promote learning experience taking position(McCabe \& O'Connor,2014) not in the centre stage but the side stage. O’Neil \& McMahon identified some core principles of SCL: (1) active learning; (2) emphasis on active learning; (3) increased responsibility in the part of students; (4) more significant sense of autonomy in students; (5) teacherslearners interdependence; (6) mutual respects between teachers and learners; (7) reflexive approach to the teaching and learning (O’Neil and McMahon,2005; Lea, et al., 2003).

Learning literature suggests many characteristics of student-centred interactive learning:

- $\quad$ Teachers role as facilitator and guide (McCabe \& O'Connor,2014; O'Neil and McMahon,2005).

- A more significant role of media and technology (Bergmann and Sam, 2012). 
- Students role are more active, self-reflective, self-motivated, autonomous, problem-solving, inquirybased, need-based and relevant to their condition and interests (Sams\& Bergmann, 2013).

- Most of the learning is group activity based cooperative, participatory and collaborative (Felder and Brent, 1996).

- Just-in-time teaching and learning and teacher apply the methods in the classroom: do, reflect, learn and use (Bergmann and Sam, 2012).

- Most of the method and techniques are: Peer-led team learning, flipped class, pair learning, project, presentation, poster presentation, learning by doing, peer learning, lecture, (MOE,2015), demonstration, site visit, study tour and field visit, group discussion and pair discussion, panel discussion, case study, brainstorming, role play, guided study, simulation game, individual assignment, group assignment, problem solving, question-answer method, interactive learning, STAD (student teams-achievement division) (Savery and Duffy, 1995).

- All three process of learning included: cognitive, Affective and psychomotor domain. Besides these three processes all stages of learning involved in interactive learning: remembering, understanding, applying, analysing, evaluating and creating (Mezirow, 1997)

- Role of teacher in this approach: managing the class, organising, moderating, innovating, exhibiting, directing, maintain justice, encouraging, consulting, acting as a role model, planning, observing, dreamer (McCabe \& O'Connor, 2014).

- Role of student: Good listener, punctual, persistent, raise questions, inquisitive, active participation, positive, self-motivated, self-reflective, responsible, creative, dreamer, tolerant, self-conscientious, leader, pragmatic, competent, thoughtful (MOE,2015).

\subsection{Effectiveness of traditional Learning versus SCL}

The first argument for the traditional lecture is managing a large classroom in a limited facility, inadequate number of teachers, no training for the teacher, technological insufficiency and disciplinary dimension. Besides the assessment and evaluation of such a large number of students is related to this issue, as well. Consequently learning proved ineffective, unemployment generating, non-reflective, killing of innovativeness and creativity, incompetent to world standard and finally, loss of valuable human time, resources, labour, energy, merits and efforts.

In contrast, interactive or SCL proved highly effective, result oriented, reflective, innovative, participatory, popular in students, addressing three core issues of teaching-thinking, reasoning and learning. Moreover, it is proved proficient to prevent education business, exploitation with education, dependency on private tuitions, guide and notebook, copying and cheating in examination, reducing the dropout rate, plummeting truancy and deviated behaviour in educational institutions (MOE, 1997). The core challenge for this method it can be individualistic, high performing students can lose interest, some can hitchhike doing nothing in the case group work projects, some oppose it both from teacher and students, it is highly resource, time, space, technology-oriented those are found scares in Bangladeshi context. Teachers' motivation, training, culture, the political culture of the society, 
attitudes, motivation, and sincerity of educators also do a matter. The latter part of this essay will discuss the suggestion or plan overcoming the challenges mentioned here.

\subsection{Critical Reflection}

\subsection{Current practice}

At present in Bangladeshi college education, it is considered that the depth of knowledge, loud voice, commanding personality, oratory, strict sense and practice of discipline in the classroom are the highest quality to be a good teacher. But now it is observed that there are many important things related to learning and teaching. Knowing about the students, their needs, see into the soul, open heart contract with them, to touch their feeling, to reach their learning needs, to response them to stimulus, to help them as much as possible and motivate them to be lifelong learners are the heart of the quality teaching.

In my present practice, in few colleges laptop, pen drive, internet, Google, multimedia projector, and in few occasions mobile phone, become the inevitable part of my classroom instruction. Now, a college teacher in a college with higher education has been conducting classes in $1^{\text {st }}$-year honours, $2^{\text {nd }}$-year honours, $3^{\text {rd }}$-year honours, $4^{\text {th }}$-year honours, masters previous, masters final year, non-major sociology $2^{\text {nd }}$ year for other social sciences departments and Higher Secondary (xi and xii grade) classes.

\subsection{Preparation for conducting a proposed class following SCL approach}

Every course needs at least 60 instruction class hours as stipulated by syllabus or curriculum by the NU (for undergraduation and post graduation) and board (for xi and xii).In practice it is not possible for so many reasons: vacation, leave, holidays, political unrests (in some cases), classroom shortage, exam schedule, unscheduled class suspension (in every long vacation- after and before, at least seven working days- most of the students do not attend classes). Considering this reality, we developed multimedia lectures for 55 classes and rested five days for reviewing the syllabus for each course. In 60 minutes of class duration, it takes five to eight minutes for attendance, eight to ten minutes for reviewing previous class, five minutes for concentration and stimulating questions from me to students and brainstorming, 10 minutes introduction with PowerPoint, 15 minutes elaboration and explanation with PPT, 10 minutes interactive QA session and five minutes conclusion. Often, we take 20 to 25 minutes class test, but it is a too difficult task to evaluate the scripts and giving them feedback considering our fewer logistics support and other workloads. Sometimes give them an individual assignment, but often we do not allocate time to evaluate it for large in number. We found in most cases a few students take it seriously but most of them just copying from the guidebook with lots of irrelevant data and discussion. All most all the cases we have limited scope to give the person to person feedback for time constraint along with encountering large in number.

The students also have little interests as no marks added by such kinds of activates to their final result prepared by the NU.

Also, we conduct at least two workshops in each academic year, and we find it useful apart, and a portion of students enthusiastically take part in them, but most of them show escapist attitudes. Considering large numbers and time constraints, we cannot employ sufficient attention and time; accordingly, these activities bring a change a little in a practical sense. It is generally believed that most of our students enter our institutions with a sea of 
disappointment, find their institution less helpful to cherish their dreams, find a few examples of success stories from NU graduates, culturally NU considered the least status institutions and summative assessment system make them entirely passive, apathetic, hopeless, aimless certificate seekers. Those certificates did not show them any light shortly except adding with a little status in their social life.

\subsection{Evaluating the researchers' current practice}

SCL approach suggests a lot about teaching and learning. Theories about learning: cognitive, meta-cognition, constructivism, existentialism, reflective theory, essentialism, progressivism, perennialism, reconstructionism, methods and techniques: formative assessment, peer assessment, summative assessment, active learning, reflective thinking and learning and so on. These theories, concepts, ideas make instructors thoughtful and re-evaluative in the educating environment.

Now, it is found that Bangladeshi teaching process only a little productive in the long term as well as student's creativity, in the most cases, is being killed, their reflectivity remained uncovered, their potentiality stays unused, and merely they become the prototype of the current social reality. We may present some instance from our societywe teach democracy in our community for almost a century but it is not internalised in our behavioural pattern, we teach good governance but achieving it remains a far cry, we teach technology but nowhere we achieve state of the art technology in our own, we teach medical science, but millions of people go abroad for medical treatment each year, we teach politics, and we have thousands of politicians but no leader or statesman, we teach tolerance and peaceful coexistence, but we have unsolvable conflict centred by intolerance. Therefore it can, from this point of view be considered a complete failure of our education system. It failed to stimulate our thinking, unsuccessful in changing our mindset positively (Hossain and Khan,2014), ineffective to reshape our personality reflectively, become futile to sharpen our creativity, useless to make us innovative and above all become abortive to prepare our learners at least problem-solving leader in political life.

\subsection{Action Plan}

Above discussion suggests that now we need a paradigm shift from teacher-centric learning to student-focused learning in our education including my undergraduate classroom. It is the time to take a holistic approach to reallocating our education as we observed any ad hock basis decision not produce expected result in such a complicated situation. So far four education policies and eight commissions or committee do not generate desired output in the education because education is related to some non-educational factors. Thereby, if we expect a reliable result, we require addressing the issue comprehensively and holistically.

In this respect, we can take help from the functionalism of People in sociology. The theory suggests that a society functions and maintains its equilibrium through four subsystems: (1) social system- maintain integrity of the society through socialisation; (2) cultural policy- related to idea, values, belief, behavioral pattern; (3)biological system- economic activities for survival that is related to social resources; (4) personality system that means polity or state or policy related issues. In brief, this idea explains the idea that any social action under a subsystem associated with the other three systems like our nervous system in the body where nothing can function isolated 
— pain in toe or grain off course related to brain and other organs. Likewise, society works as a whole equilibrium.

Education is in sociology a process of socialisation that occurred through internalisation of values (Turner, 1995).

A social system in the diagram

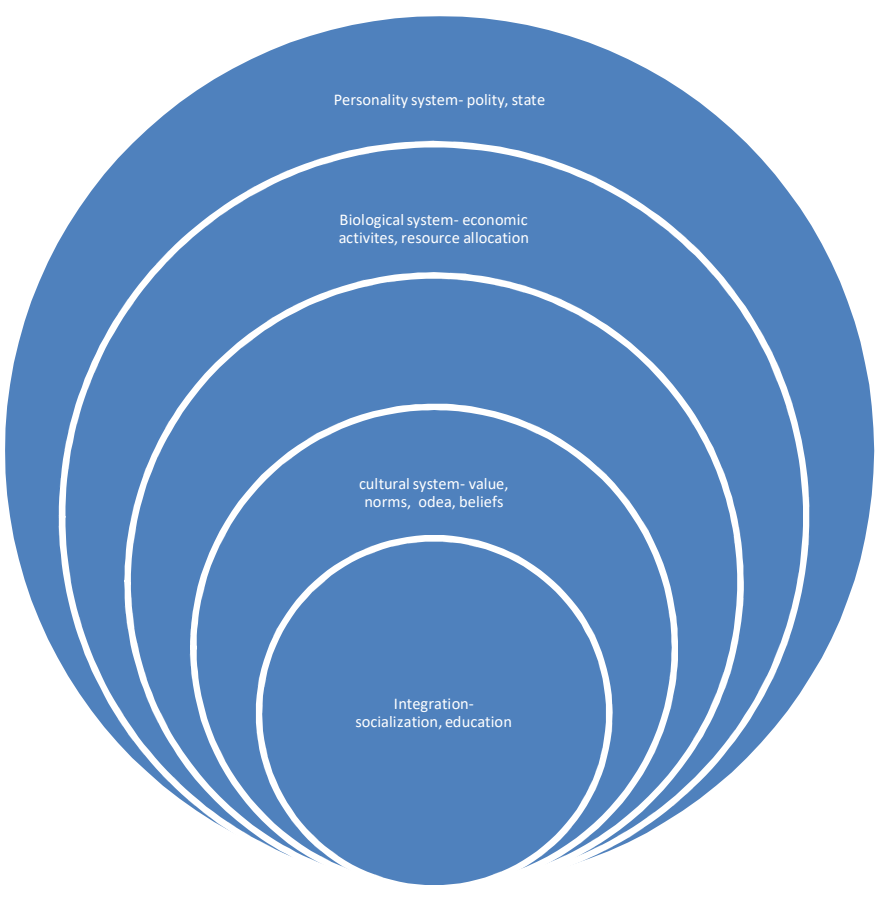

Note: The diagram developed to show the relationship between social subsystems by the author based on Parson's theory of Functionalism (Turner, (1995).

According to functionalism change occurred in society through four processes: (1) differentiation; (2) adaptive upgradation; (3) Inclusion; (4) value generalisation. Now Bangladesh needs to address all four systems targeting change in the entire four processes.

We need to change in education through internalisation of new values that implies interactive student-centred learning in the classroom. It entails that we need changing in (i) social structure if we want to improve the education system of a society. Without a change in a social setting, it is not possible to change the note, guide, coaching centres and certificate oriented education. If we want to change it, we have to change our existing (ii) beliefs, the pattern of behaviour, ideas, norms and values related to education. We need to internalise into our students' mind that the aim of education is not merely achieving grade or certificate, but it is internalising values and life skills. (iii) State and policymakers have to understand state's foremost priority is to educate its new generations in an accomplished manner to face the challenge of the $21^{\text {st }}$ century, and therein they have to ensure 'no child left behind' 'teachers are respected' and 'no politics with education'. Finally (iv) we need to allocate more than necessary resources in education for the wellbeing of our state, army, science and technology and above all for the future of the nation.

\subsection{Strategies and Techniques}

Forming strategy we need to address it all three levels: (1) Administrative; (2) Facilities or resources; and (3) teachers training. Just, in a nutshell, we put forward some issues that can help to overcome the present crisis. Policy and administrative: we would humbly propose that some policy, regulatory and resource issues should be 
addressed first as institutional learning is a general issue. Thereby my conviction is that: lessen number students in a classroom, providing necessary resources, training of teachers with the latest development in teaching and learning are essential prerequisites. Without fulfillment of those prerequisites, SCL cannot be effectively implemented in the classroom. Keeping this reality in thinking we chalk out a plan for my postgraduate class in my college. In our practice, we cannot change or introduce anything new in the classroom without the policy support and administrative support of the authority. We hope with the appropriate support from our administration we can implement our plan in the classroom.

As a strategy we would take some points to enhance in the classroom learning. That is: (1) adopt more autonomy to the student as far as possible; (2) attempt to make them active in learning especially acquiring knowledge with self-motivation; (3) make them conscious about what and why they learn; (4) try to make them convince on becoming interactive in learning with the fellow people; and finally make them about transferable skill that help them bring success in professional life(O’Neil and Mcmahon, 2005).

\subsection{Implementation}

In the beginning, it should prioritise the needs according to available facilities and propose to the authority for further improvement. First, it should make a series of lesson plans for every course and implement them in the classroom for better learning. Practices to experiment within classes include a range of SCL learning methods and techniques. A list of possible options follows below.

- Taking a brief assessment in every class

- Involving group activities, for example, taking short feedback from each bench (considering a group as attendants are large)

- Taking a group assignment within five sentences in the classroom

- Inviting them in the stage with higher frequency to present relevance, identifying and solving the problem of their society (John R. Savery and Thomas M. Duffy,1995)

- conducting a workshop as a higher number as possible

- Arranging a flipped class with the help of ICT and increasingly involved e-learning (Karmakar and Wahid, 2000).

- Creating a WhatsApp group and Facebook group for each course and give them feedback through these and create an opportunity for 24/7 learning.

- $\quad$ Giving short assignment higher in number

- Assign project based on Bangladeshi society for example 'Prepare a short planthat how far conflicting politics influence your neighbourhood/ village and how you contribute to reducing this kind of practice as a student'.

- Improvement of their learning outcome and internalising values we will introduce peer monitoring system among the students.

- Create a window for expression of critical thinking of students, for example, publishing journal from the department, poster competitions (fixed topic based), Visualisation in Participatory Program (VIPP) card practice, debating (we are practising) running language club (it is in preparation).

- Assign small scale survey for a group as in sociology; social research is a significant activity.

- In the time of assignment, we will encourage them to practice more freedom of choice to select topic and subject.

- Influence the students to publish an article in newspapers that will make them innovative and reflective.

- Strictly follow lesson plan in the classroom that can bring a momentum as we believe.

- Encourage and arrange a field trip for the fulfilment of project and portfolio.

- Try to make some window for collaborative learning with institutions within our reach.

- Attempt practising self-assessment and peer assessment of assignment, projects and stage performances. 


\subsection{Prospective complexities in Implementation}

Some researches suggest that in exercising SCL in practice some raising some hurdle is not unexpected especially from adult learners. O'Sullivan (2003) opined that it is not appropriate for developing countries where there are scares resources is an obstacle. Simon (1999) in the opinion that it focused on individual learners so that weak learners can affect severely. In our classroom, we expect some highly extrovert student can make a problem for other introvert students as we are to deal with a large number of students. Some of the learner's impression is approximating to that it is not more than gossiping or passing the time in a tea stall. Some students want to dominate the situation without knowing the whole things. Some are denied group work, and some are want to take credit doing nothing.

In that case, we need to follow two essential procedures: (1) motivational and (2) technical and motivational. In the first, we credibly explain to them that it is not an experiment or playing game; it is the way that will bring them success in life. Similarly, we try to convince them about meta-cognition and self-motivated learning that can get a good number of denial groups in the right track. Accordingly we can apply some techniques to reduce such kind of difficulties: (a) we intelligently monitor the group works and identify students with evasive attitudes and assign them some particular type of job; (b) rotating job cleverly; (c) finding out some strong and weak aspects of slippery learners and make scope of show their strength and unfolding some weak points through performance, hope those will help us to manage to dominate characters, and trouble willful trouble makers; (d) involving students more and more creative and innovative activities in group and individual tasks will help the students finding increasing level of happiness in their activities hope they will incrementally become attentive to the searching knowledge and skills.

In sum, it is found two complicated problems that cannot be solved without administrative steps: absenteeism culture among the students and even segments of the teaching faculty. If the administration, with extended visionary policy, will take gradual steps to address them then our intuitive will produce expected flowers and fruits. In the beginning, may we have some constraints but it can be removed applying the natural psychological process that is: Shock, denial, prevailing sentiment, resistance and withdrawal, struggle and exploration, the return of confidence, integration and success (Felder and Brent1996).

\section{Conclusions}

This study may not be well-articulated one as we attempt to present the existing practice in college education in Bangladesh and find out its loopholes in imparting important education. Following the finding of the study it is to be suggested some way out to put into practice the SCL method in learning to teach in our practice. We have numerous limitations in the ground, but with our meticulous efforts, we can overcome a large section of hurdles by taking and sharing new knowledge and ideas from the field of learning researches, for example, SCL and interactive learning. We find some obstacles from our social practice, some from our motivation, a part of them related to resource constraints and short administrative comings. In the journey of changing in education in our classroom, student's cooperation, motivation and value standard are also essential factors. With the collaboration of policymakers administration, policy support from education administration and changing our motivation towards SCL as well as arduous efforts can make it possible to new types of active transformative learning.

The current Bangladesh education system can make a student feel like a square peg in a round hole. Our classroom is not an exception to this ground reality. That is why it has been the conviction that the time is ripped more than enough for reforming the education system of Bangladesh and put the education in the right track of interactive and student-centred learning which stimulating creativity and critical thinking of learners. It will make our learners active in learning, self-reflective, motivated, meta-cognitive, need-based problem solving, anywhere and everywhere learners, not only, knowledge seeker but also knowledge creator. The policymakers must change their attitudes towards education and allocate the highest possible resources for education (at least $20 \%$ of the national budget) as well as address crucial administrative area in no time. Though some colleges in Bangladesh are ageold, there are many shortages of establishing SCL and interactive learning. We have the confidence, with the policy, administrative and resource support from appropriate authority the methods and techniques we suggest help profoundly in executing SCL undergraduate classroom in colleges as well as in other institutions. Thereby active and meaningful learning which will become the 'gateway to life' and 'the treasure within' in the life of our students who attend our class with their future dream to be fulfilled. Besides, we can achieve the nation's longcherished goal of education: learning to know, learning to do, learning to live and learning to be. 


\section{References:}

Alamgir, Mohiuddinand\&Haque, Moinul, (2018, June 06). Local education fails to meet RMGsector needs, the NEWAGE, PP-1.

Alamgir, Mohiuddin, (2018, June 30), Public Universities Keep Little Budget for Research, The New Age, P.1-2

Abeysekera, L., \& Dawson, P. (2015). Motivation and cognitive load in the flipped classroom:Definition, rationale and a call for research. Higher Education Research \& Development, 34(1), 1-14.

Barak, M., Lipson, A., \&Lerman, S. (2006). Wireless laptops as a means for promoting activelearning in large lecture halls. Journal of Research on Technology in Education, 38(3), 245-263.

Bergmann, Jonathan and Sam, Aaron, (2012), Flip Your Classroom, Washington DC: ISTE.

Byers, T. et al., (2018). Empirical evaluation of different classroomspaces on students' perceptions of the use and effectiveness of 1-to-1 technology. British Journal of Educational Technology, 49(1),153-164.

Felder, Richard M. and Brent, Rebecca, (1996), Navigating the Bumpy Road toStudent-Centered Instruction, College Teaching, Vol-44, No-2, 44-47.

Habib, Wasim bin, (20172, June 2), Problem in Education: Quality not priority, The Daily Star, P-4

Hossain MdMoazzom and Khan, Amir Mohammad, (2014), Higher Education Reform in Bangladesh: An Analysis, Mediterranean Journal of Social Sciences, Vol-5, 423-427.

Karmakar, C. K., \& Wahid, C. M. (2000). Recommendations for Bangladesh towards e-learning Readiness. Department of computer science. Shah Jalal University of science and technology, 97-102.

Khan, M., Hossain, S., Hasan, M., \&Clement, C. K. (2012). Barriers to the introduction of ICT into education in developing countries: The example of Bangladesh. Online Submission, 5(2),61-80.

Khan, S. H. (2014). A model for integrating ICT into teacher training programs in Bangladesh based on TPCK. International Journal of Education and Development using Information and Communication Technology, 10(3), 21.

Kim, K., Sharma, P., Land, S. M., \& Furlong, K. P. (2013). Effects of active learning on enhancing student critical thinking in an undergraduate general science course. Innovative Higher Education, 38(3), 223-235.

Lea, S. J., D. Stephenson, and J. Troy (2003). Higher Education Students' Attitudes to Student-CentredLearning: Beyond' educational bulimia'. Studies in Higher Education 28(3), 321-334.

Ministry of Law, (2016). Article-17, The Constitution of Bangladesh, Dhaka: BG Press.

Mezirow, J. (1997). Transformative learning: Theory to practice. New directions for adult andcontinuing education, 1997(74), 5-12.

McCabe, A., \& O'Connor, U. (2014). Student-centred learning: the role and responsibility of the lecturer. Teaching in Higher Education, 19(4), 350-359.

Mahmud, K., \&Gope, K. (2009, December). Challenges of implementing e-learning for higher education in the least developed countries: a case study on Bangladesh. In Information and Multimedia Technology, 2009. ICIMT'09. International Conference on (pp. 155-159). IEEE.

MOE (Ministry of Education), 2010, National Education Policy, Dhaka: Government of Bangladesh.

MOE, (2015), Curriculum 2012 dissemination Master Trainer Training Manual, Dhaka: National Curriculum and Text Book Board.

MOE (Ministry of Education), 1997, National Education Policy, Dhaka: Government of Bangladesh.

O’Neill, G., \& McMahon, T. (2005). Student-centred learning: What does it mean for students and lecturers? In Emerging Issues in the Practice of University Learning and Teaching, Dublin: AISHE. P. 28-36.

Rahman, M. et al. (2016).Budget for Education in Bangladesh: An Analysis of Trends, Gaps and Priorities, Dhaka: CPD

Sams, A., \& Bergmann, J. (2013). Flip your students' learning. Educational leadership, 70(6), 16-20.

Savery, John R. and Duffy, Thomas M.(1995), Problem Based Learning: An instructional model and its constructivist framework, Educational Technology, 1995, Vol-35, 31-38.

Rahman, Habibur and Chaowdhury, Al Faruk, (2017) Rajshahi College Magazine,Rajshahi: Rajshahi College Publications.

Tietjen, Karen et al. (2004). Time to Learn: Teachers and Students use Time in Government Primary School in Bangladesh, Washington DC: BEPS.

Turner, Jonathan H., (1995), The Structure of Sociological Theories, Jaipur: RawatPublications. 


\section{Appendix-1}

Model lesson plans are presented here for better understanding:

\section{Model Lesson plan-1}

A lesson plan is prepared for the Honors $1^{\text {st }}$-year sociology class on the course of 'Political Sociology', chapter two, lesson title- 'Political Culture'.

\begin{tabular}{|c|c|c|c|c|c|}
\hline Time & Content & Teacher activities & Student activities & Aid & Feedback \\
\hline $\begin{array}{l}9.00- \\
9.05\end{array}$ & $\begin{array}{l}\text { Start with a still picture } \\
\text { and asking the students } \\
\text { about the image and } \\
\text { show the Title of } \\
\text { today's class }\end{array}$ & $\begin{array}{l}\text { Starting the projector and } \\
\text { show the picture }\end{array}$ & $\begin{array}{l}\text { Brainstorming and } \\
\text { participation }\end{array}$ & $\begin{array}{l}\text { MM } \\
\mathrm{P} / \mathrm{W} \\
\text { hiteb } \\
\text { oard }\end{array}$ & Visual \\
\hline \multirow[t]{3}{*}{$\begin{array}{l}9.05- \\
9.15\end{array}$} & $\begin{array}{l}\text { Show the objective, } \\
\text { lesson outcome and } \\
\text { introduction of the } \\
\text { content, definition with } \\
\text { an example. }\end{array}$ & $\begin{array}{l}\text { Talking and questioning } \\
\text { (fewer)/ provide a hand } \\
\text { sheet/ concise not sheet }\end{array}$ & Listening & $\begin{array}{l}\mathrm{MM} \\
\mathrm{P} / \mathrm{PP} \\
\mathrm{T}\end{array}$ & visual \\
\hline & $\begin{array}{l}\text { Lesson objectives: (1) } \\
\text { to know the students } \\
\text { about PC; (2) to the } \\
\text { political PC of } \\
\text { Bangladesh. }\end{array}$ & & & & \\
\hline & $\begin{array}{l}\text { Lesson outcome: (1) } \\
\text { students can describe } \\
\text { the main idea of PC; } \\
\text { (2) students can } \\
\text { explain PC of } \\
\text { Bangladesh; } \\
\text { students cab set } \\
\text { example about PC of } \\
\text { their society. }\end{array}$ & & & & \\
\hline $\begin{array}{l}9.15- \\
9.9 .18\end{array}$ & Introduction & Monitoring around & Pair sharing & - & $\begin{array}{l}\text { active } \\
\text { participation }\end{array}$ \\
\hline $\begin{array}{l}9.18- \\
9.25\end{array}$ & Introduction & Facilitate & $\begin{array}{l}\text { Group work: a row (I } \\
\text { have three rows) or } \\
\text { bench ask example } \\
\text { from their society } \\
\text { according to learning, } \\
\text { other than set by me, } \\
\text { each group have to } \\
\text { mention a new one. }\end{array}$ & - & $\begin{array}{l}\text { Active } \\
\text { learning }\end{array}$ \\
\hline $\begin{array}{l}9.25- \\
9.40\end{array}$ & $\begin{array}{l}\text { Explaining } \\
\text { describing types of } \\
\text { political culture }\end{array}$ & $\begin{array}{l}\text { Talking with the help of } \\
\text { PPT }\end{array}$ & $\begin{array}{l}\text { Listening and } \\
\text { visualising }\end{array}$ & PPT & $\begin{array}{l}\text { Short } \\
\text { assignment } \\
\text { (consisting not } \\
\text { more than ten } \\
\text { sentences, } \\
\text { considering } \\
\text { large in } \\
\text { number) }\end{array}$ \\
\hline $\begin{array}{l}9.40- \\
9.45\end{array}$ & Do & $\begin{array}{l}\text { Facilitate, taking note of } \\
\text { their question and answer }\end{array}$ & $\begin{array}{l}\text { One bench ask other } \\
\text { (randomly) about in } \\
\text { which rype } \\
\text { Bangladesh belongs }\end{array}$ & - & $\begin{array}{l}\text { visual/by } \\
\text { observing }\end{array}$ \\
\hline
\end{tabular}




\begin{tabular}{llll}
\hline & & & to regarding political \\
defend \\
culture and destioning
\end{tabular}

\section{Model Lesson plan-2}

Class: Honors $1^{\text {st }}$ year

Subject/ Course: Sociology/ Political Sociology Chapter: $6^{\text {th }} /$ Social Movement

Lesson Title: Liberalism

Learning Outcome:1. Learners will be able to describe what liberalism is;

1. ... what are the key features of liberalism

2. ... what are the shortfall of liberalism

3. ... what are the differences between liberalism and conservatism.

Types of equipment and instruments: marker, board cleaner, laptop, multimedia projector, poster paper, colour pen, adhesive.

\begin{tabular}{|c|c|c|c|c|}
\hline $\begin{array}{l}\text { Time } \\
60.00\end{array}$ & $\begin{array}{l}\text { Stages of the } \\
\text { lesson plan }\end{array}$ & $\begin{array}{l}\text { Learning and teaching activities for } \\
\text { teacher }\end{array}$ & Activities for learners & $\begin{array}{l}\text { Extra } \\
\text { information }\end{array}$ \\
\hline 05.00 & $1^{\text {st }}$ & greetings and attendance & $\begin{array}{l}\text { hearing and } \\
\text { participating }\end{array}$ & \\
\hline 05.00 & $2^{\text {nd }}$ & verifying prior knowledge & $\begin{array}{l}\text { hearing and } \\
\text { participating }\end{array}$ & \\
\hline 20.00 & $3^{\text {rd }}$ & $\begin{array}{l}\text { presenting lesson with laptop and } \\
\text { MMP }\end{array}$ & $\begin{array}{l}\text { visualising and } \\
\text { participating }\end{array}$ & \\
\hline 10.00 & $\begin{array}{l}4^{\text {th }} \text { group } \\
\text { work/poster } \\
\text { presentation }\end{array}$ & Instructing and monitoring & $\begin{array}{l}\text { students write five } \\
\text { features of liberalism } \\
\text { in the poster. } \\
\text { involving group work } \\
\text { and cooperating }\end{array}$ & $\begin{array}{l}\text { set poster in } \\
\text { the wall }\end{array}$ \\
\hline 10.00 & $5^{\text {th }}$ stage & presenting and lecturing & $\begin{array}{l}\text { visualising and } \\
\text { hearing }\end{array}$ & \\
\hline 10.00 & $6^{\text {th }}$ stage & question-answer and conclusion & $\begin{array}{l}\text { question-answer and } \\
\text { participation }\end{array}$ & \\
\hline
\end{tabular}

